\title{
The Infrastructural Side Effects of Geopolitics : Fortuitous Socio-Biological Modifications to Three European Borders
}

\section{Martínez, Francisco}

2019-02

Martínez , F \& Pikner , T 2019 , ' The Infrastructural Side Effects of Geopolitics : Fortuitous Socio-Biological Modifications to Three European Borders ' , Roadsides , no. 001 , pp. 18-27 . https://doi.org/10.26034/roadsides-20190014

http://hdl.handle.net/10138/303586

https://doi.org/10.26034/roadsides-20190014

cc_by_nc_sa

publishedVersion

Downloaded from Helda, University of Helsinki institutional repository.

This is an electronic reprint of the original article.

This reprint may differ from the original in pagination and typographic detail.

Please cite the original version. 


\title{
The Infrastructural Side Effects of Geopolitics: Fortuitous Socio-Biological Modifications to Three European Borders
}

\author{
Francisco Martínez and Tarmo Pikner
}

Borderlands are often presented as political landscapes characterized by fixed infrastructures that help to regulate who comes in or out of a country. In this brief essay, however, we put the focus on the triangle of (geo)politics, nature, and infrastructure by exploring what kind of socio-biological entanglements are generated along three newly established borders. These entanglements will help us understand certain aspects of how temporal regimes and socio-material arrangements are embedded in border areas. We provide snapshots of roads at the Georgian-Abkhazian borderland, the mobile frontier fences between Georgia and South Ossetia, and both vernacular and official bordering practices at the water reservoir along the Estonian-Russian border. None of these frontiers existed prior to 1991. In all three cases (situated at the periphery of Europe), geopolitical changes are perceived as disturbances marking a much longer formation time. 


\section{A liquid border on fire}

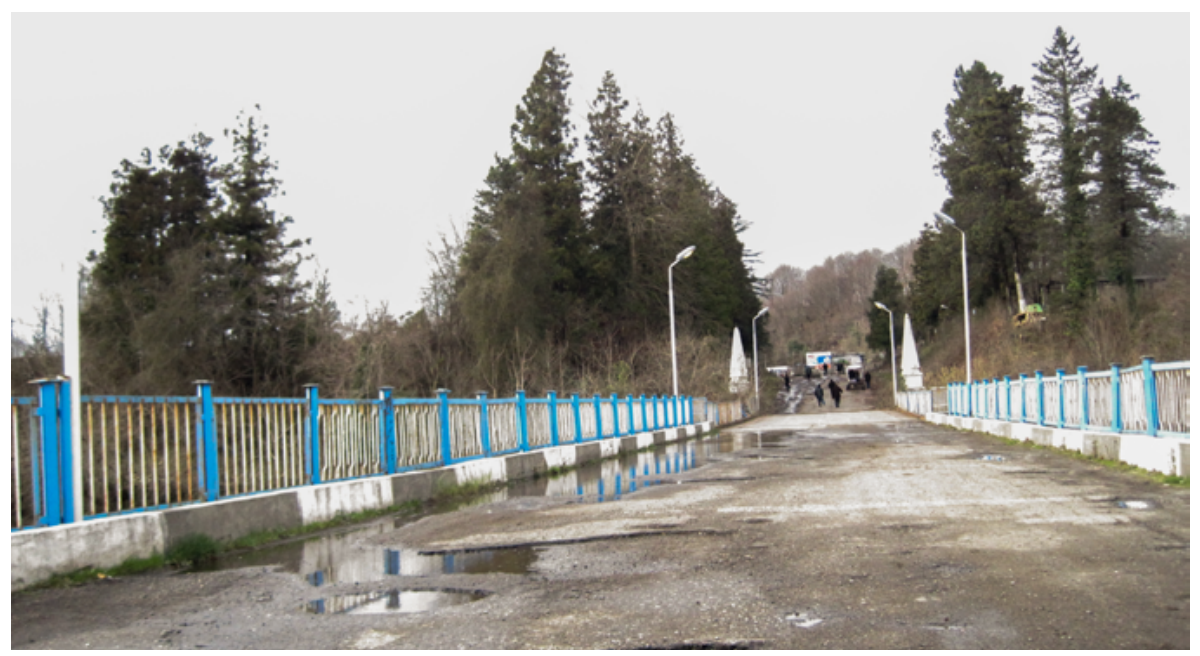

Bridge over the Enguri River, February 2010. Photo: Francisco Martínez.

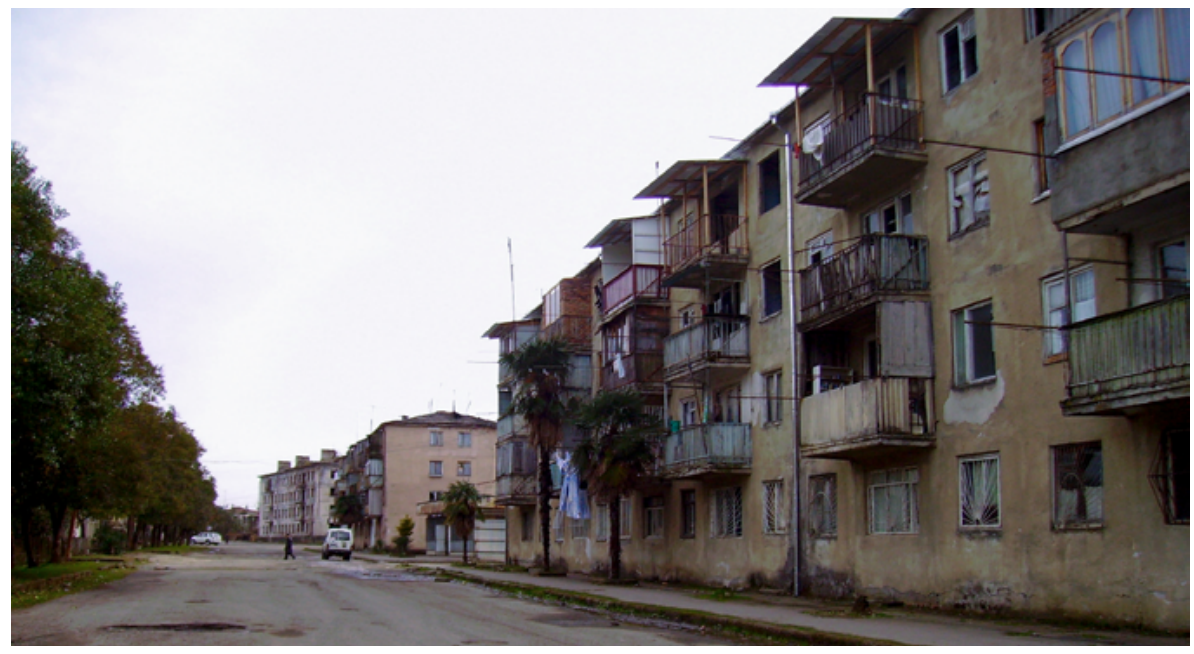

Street of Gal/i, February 2010.

Photo: Francisco Martínez.

The road through the Gal/i district requires continuous zigzagging to avoid potholes, and the landscape shows a succession of burned-out houses and skeletons of buildings. At times, the marshrutka is surrounded by cows, which would have been able to outrun us if there had been a race. One can tell that gunpowder has been used here, but also that there has been a lack of maintenance in recent years.

Field note by Francisco Martínez, 11 February 2010 
The Enguri River, or more exactly the bridge that crosses it, functions as a de facto border between two states: Georgia and the breakaway state of Abkhazia (independent since 1999, yet not recognized internationally). This frontier does not appear on any map, but nonetheless it conditions the life of the neighbouring district of $\mathrm{Gal} / \mathrm{i}^{1}$. On the northern side of the bridge, the only road providing access to Abkhazia from the south begins, with the name of the district shown in Russian, English, and Abkhazian, but not in Georgian.

Approximately 50,000 people live in Gal/i, most of them Mingrelians who returned to the area after the civil war in Georgia of 1992-1993, which was followed by further conflict in 1998 and 2008. Whereas previously it took locals half an hour to travel to Zugdidi, now it takes several hours. Even worse, only those who hold an Abkhazian passport can work in $\mathrm{Gal} / \mathrm{i}$, and just $10 \%$ of Mingrelians possess one.

Locals remain in a liminal, in-between condition due to the failure of sociopolitical relations between Tbilisi and Sukhum $/ \mathrm{i}^{2}$. This ultimately appears in the form of potholes, material decay, and crumbling infrastructure. Potholes are entropic affectations of time; they accelerate destruction much like fire. Potholes are also physical manifestations of a lack of sovereignty as well as a paucity of functioning state structures (Martínez 2019). In this case, the time regime and material arrangements of the borderland are conditioned by socio-political failures.

Mobile border in Khurvaleti,

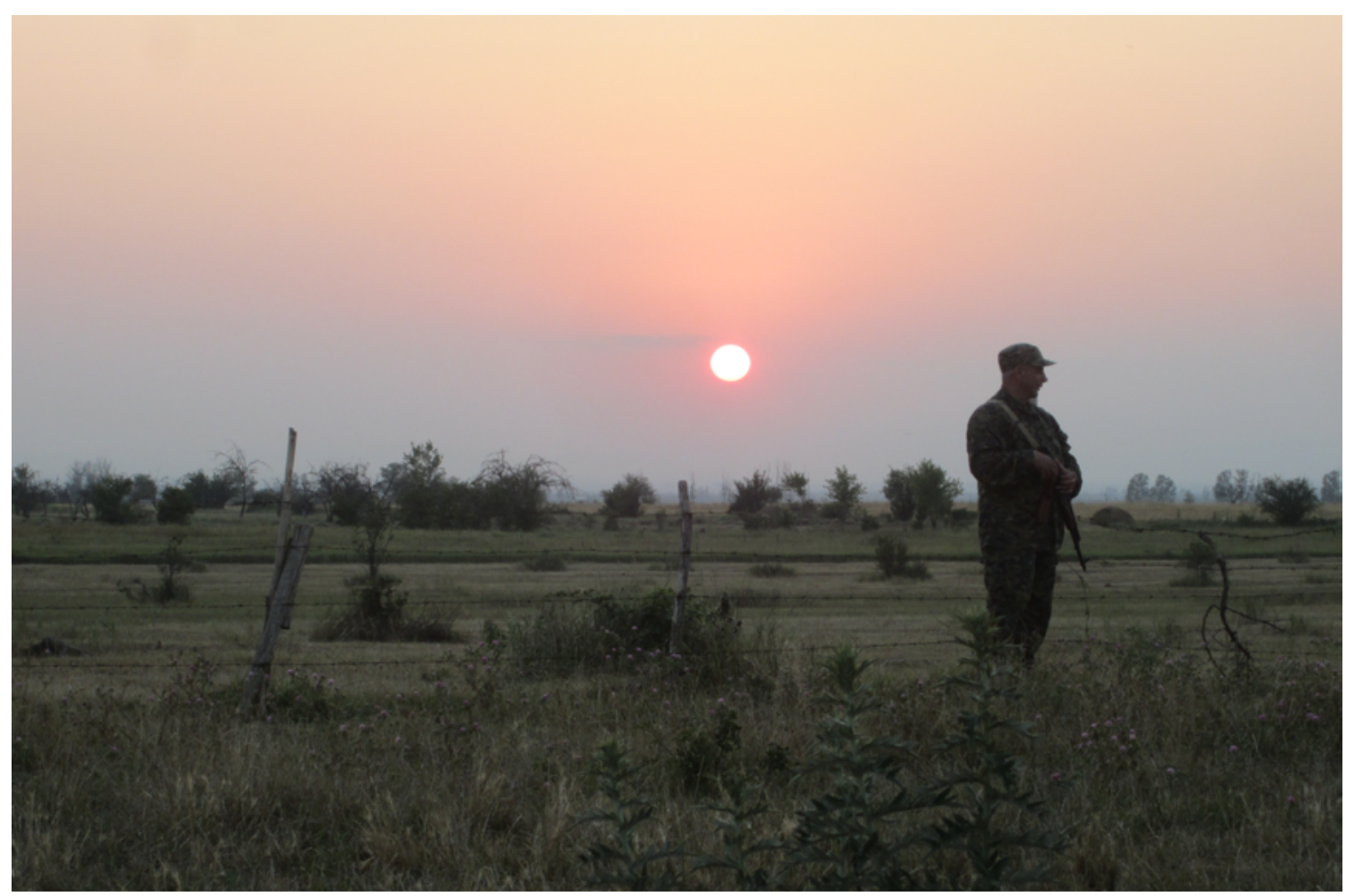




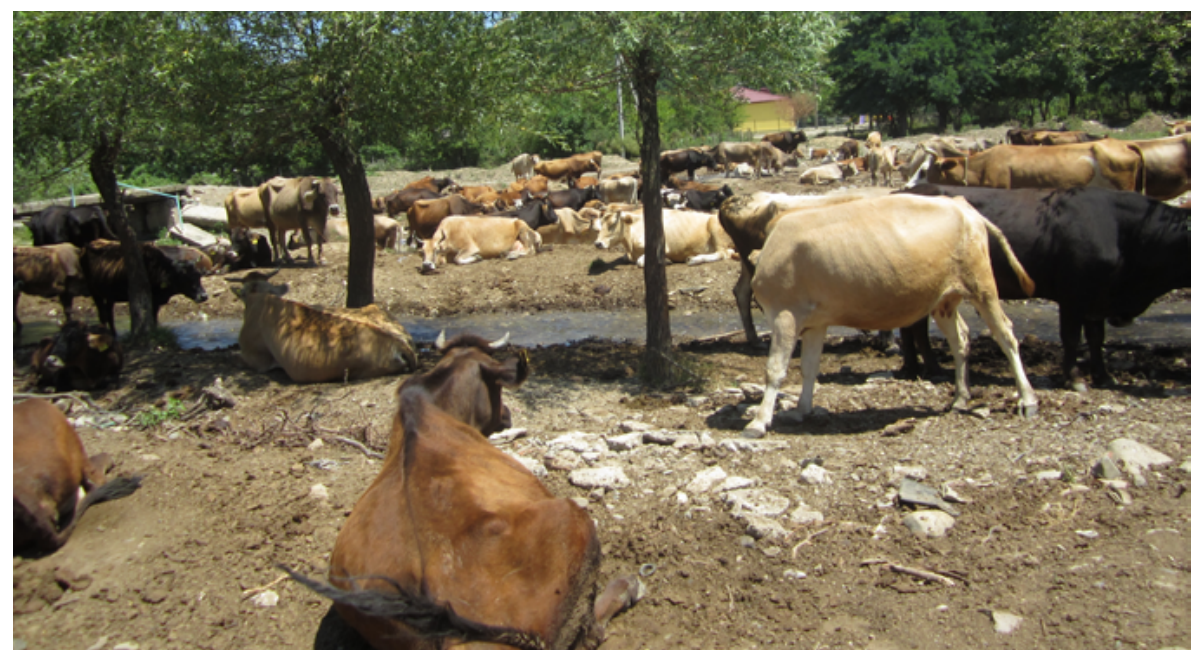

Cows next to the boundary in Dvani, July 2015.

Photo: Francisco Martínez.

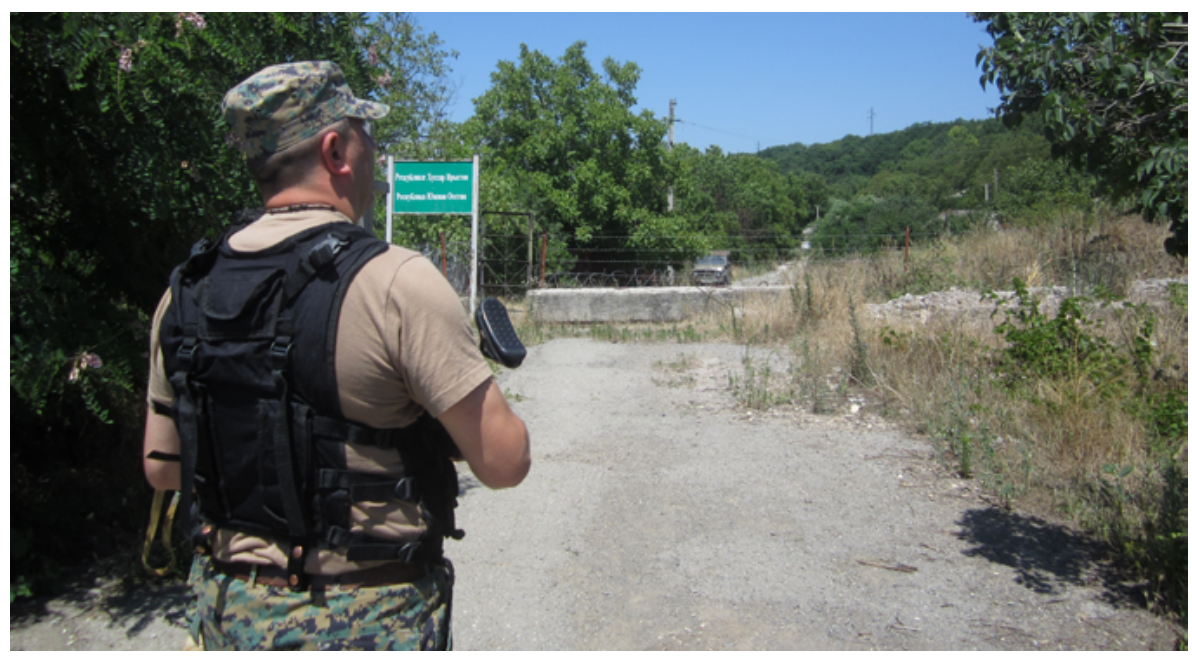

Road block in Dvani, July 2015.

Photo: Francisco Martínez.

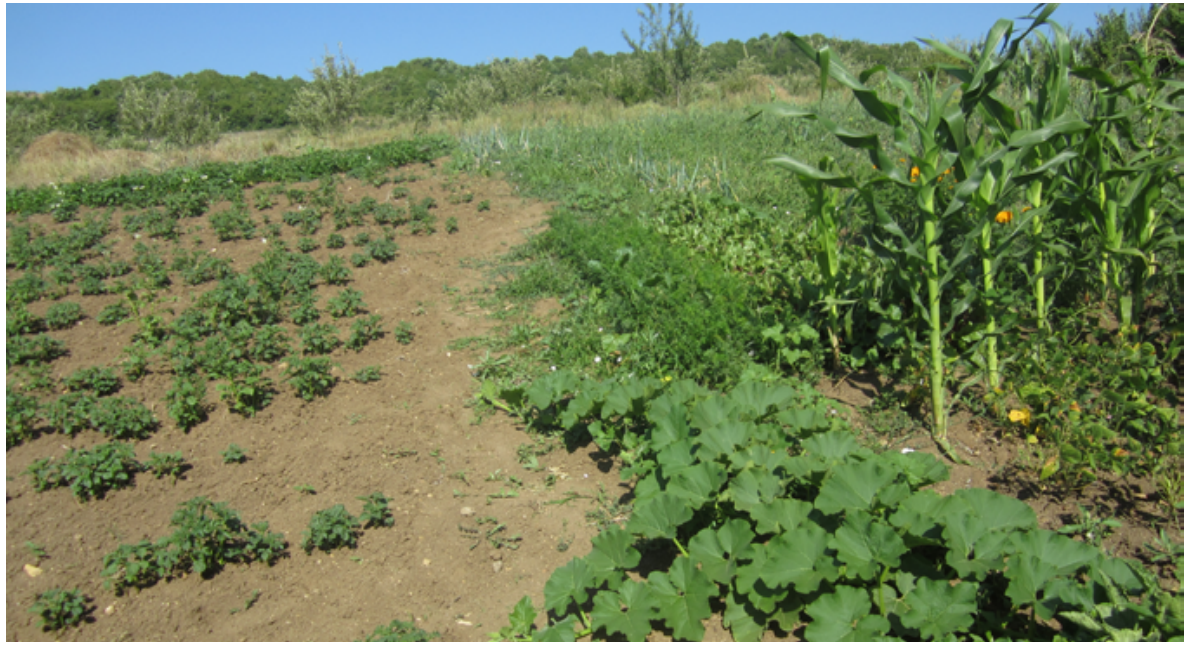

Field on the border, July

2015.

Photo: Francisco Martínez. 


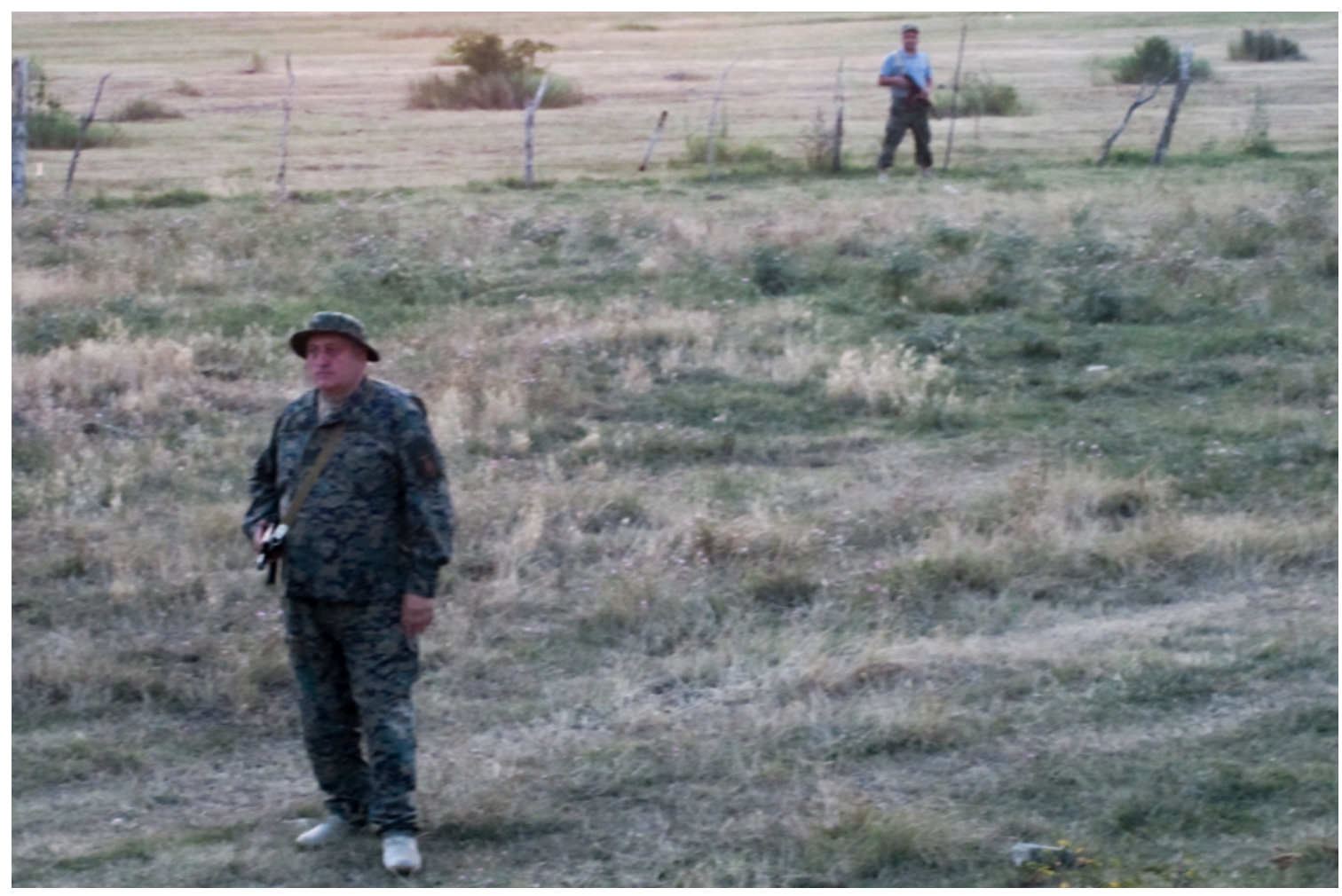

\section{An ethereal border finds its ground}

Now we go to Dvani and Khurvaleti, in the vicinity of the de facto border between Georgia and South Ossetia, to see how new geopolitical lines alter lives and landscapes. There is no distinct border here; rather, we find a mobile and, in some places, invisible boundary that sometimes takes shapes and makes itself perceptible.

Russian soldiers first started putting up fences in this area in August 2008 after the war, zigzagging their way through fifteen Georgian villages and cutting people off from their livelihoods and, in some cases, water supplies. In Dvani, a village of 1,000 inhabitants 90 kilometres away from the capital of Tbilisi, Russian and Ossetian border guards (the non-recognized independence of the latter depends on Moscow's support) erected barbed wire fences to mark the new border in September 2012. Yet, they did this half a kilometre deeper into Georgia than the previous administrative boundary line, cutting off farmlands and a cemetery. Russian and Ossetian troops still occasionally creep out after dark to move the unofficial boundary farther into Georgian territory, even if just a few yards. The makeshift fences of plastic and barbed wire are easy to move.

Concrete barriers block the roads in some places, whereas in others the boundary remains unmarked. Cows and sheep often get stranded on the Ossetian side, and when Georgian farmers go out into their fields, they might discover that the fence has been moved, turning them into geopolitical pariahs readily kidnapped by the Ossetian border police. "I myself have taken such a 'forced holiday' in Tskhinvali [on
Guarded fences in Khurvaleti, July 2015.

Photo: Francisco Martínez. 
the Ossetian side] twice while working in my own apple orchard," the local farmer Zakaria explained in the summer of 2015. Overall, almost a thousand Georgian citizens have been detained for "illegally" accessing their fields, pastures, and woodlots. As the land grabs/borderization continue, despite the European Union's monitoring mission in the region, many abandoned farms in the area revert to scrub. The temporal regime of politics has thus altered local farming.

\section{A waterline that becomes a borderline}

Since Estonia regained its independence in 1991, after the demise of the Soviet Union, the Narva River has marked the border between the Estonian Republic and the Russian Federation. In 2004, it acquired additional geopolitical meaning as the EU and NATO boundary, once Estonia became a member of these transnational institutions.

For more than 150 years, the water-rich Narva River has been pushed via infrastructure into diverse circuits, contributing to modern ways of living. Narva's hydropower previously fed Kreenholm, a large textile industry complex along the western bank. When the Estonian town of Narva on the western shore and Ivangorod on the eastern side were still a twin-town in the Soviet Union, they shared a water system of dykes, channels, locks, pumps, and pipes. After 1991, joint use and ownership of the once commonly held infrastructure was no longer possible, and both figurative and infrastructural distances grew along with the political ones (Jauhiainen and Pikner 2009).

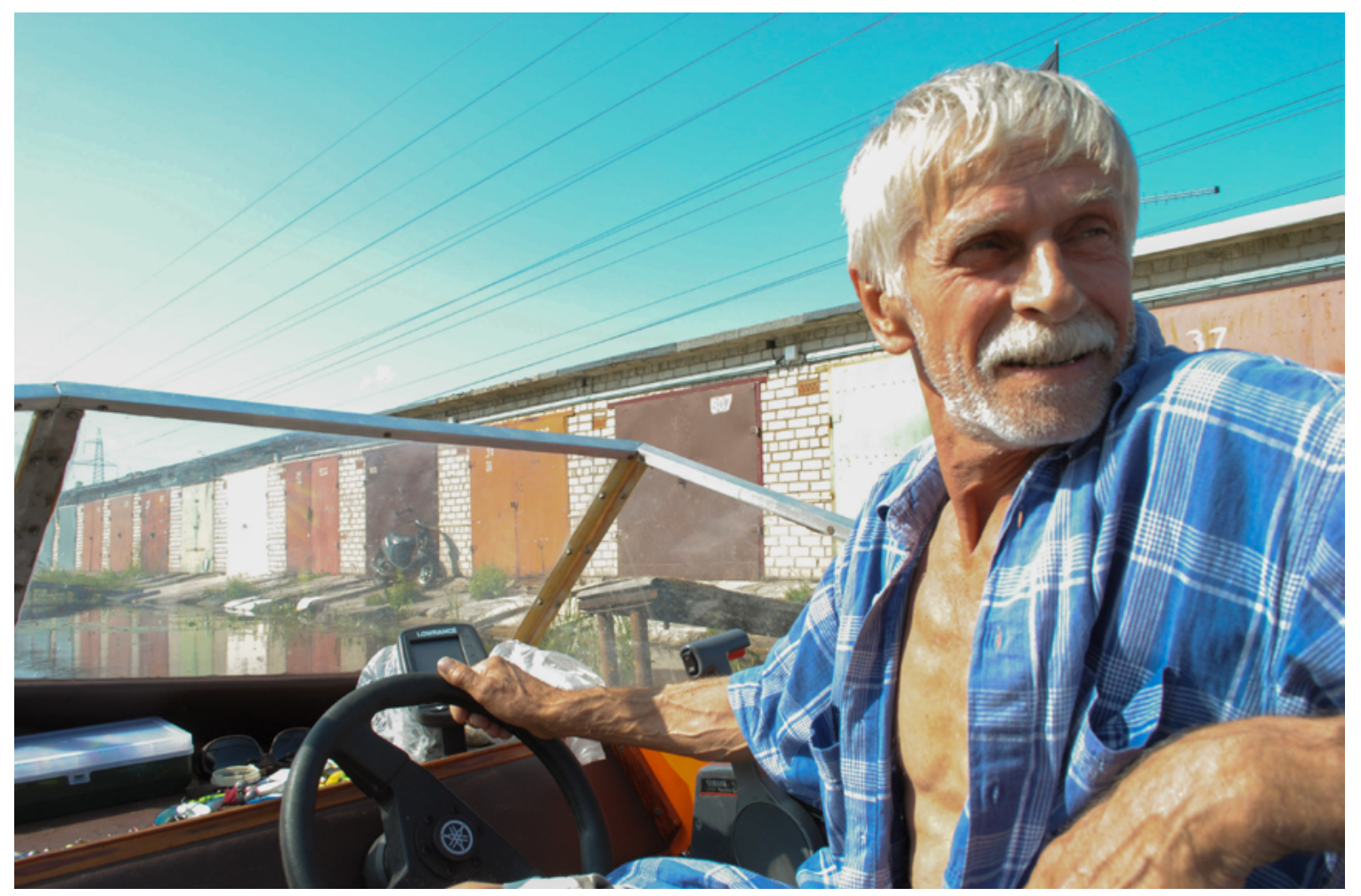


In the 1950s, the Soviet Union constructed a dam on the Narva River, creating a reservoir. Today, forty out of the basin's total 191 square kilometres belong to Estonia. The international boundary, drawn across the reservoir, is invisible to the human eye, yet it becomes manifest in the practices of accessing and maintaining the water supply. For example, the dam is partly located in Estonian territory, but it is owned

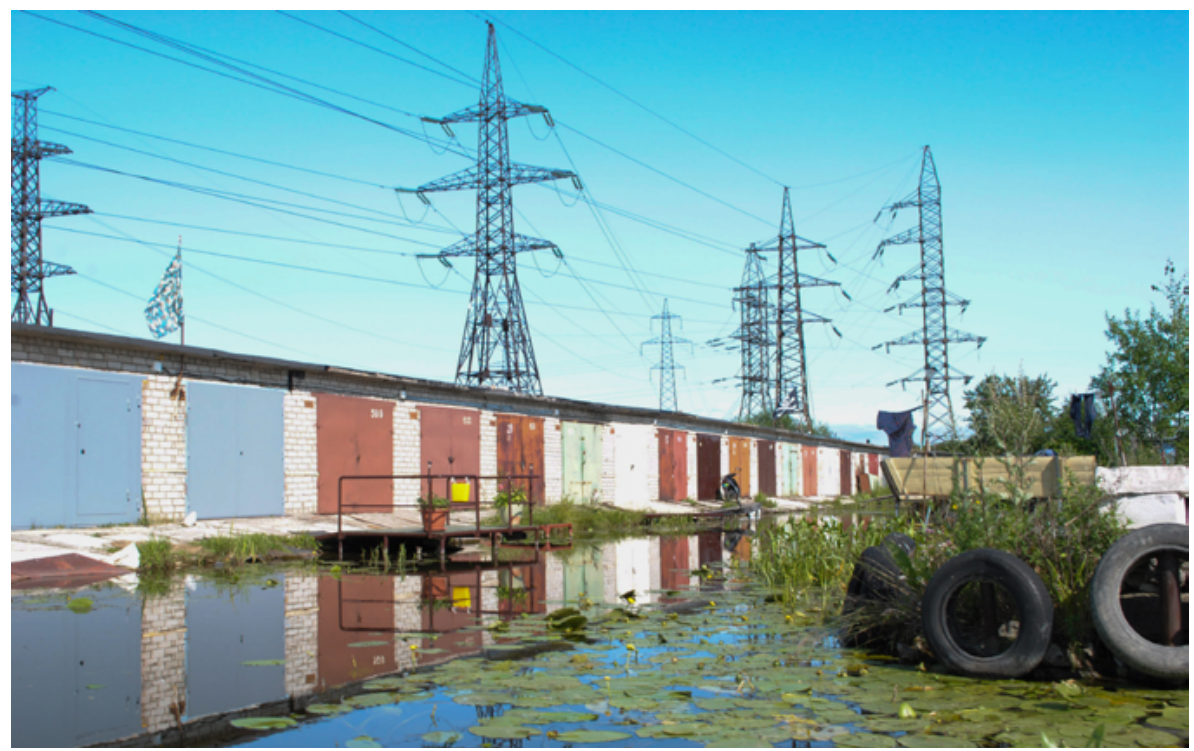

View of "Narva Venice" from canal, July 2013. Photo: Tarmo Pikner.

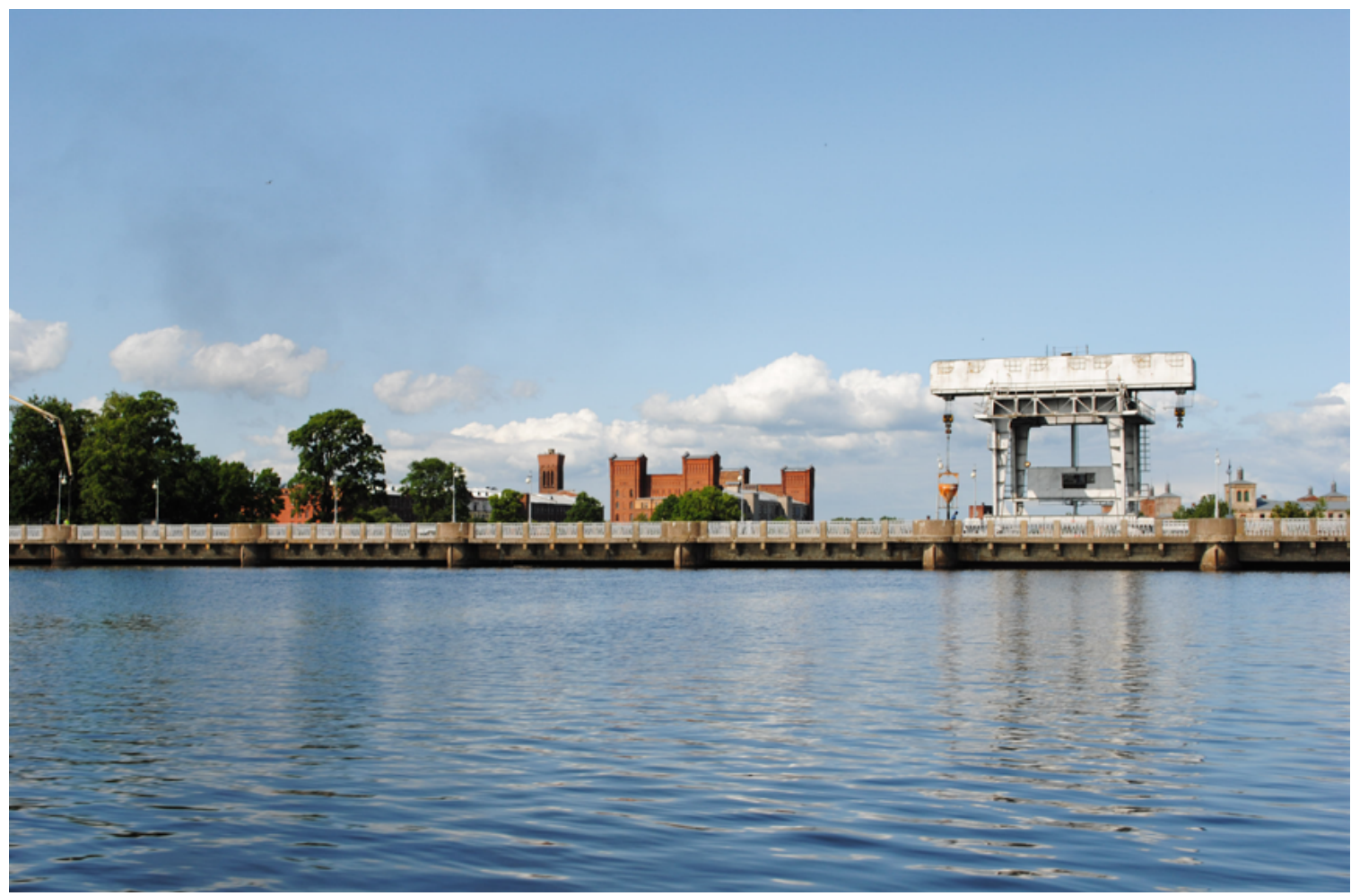


and managed by a Russian state-owned energy company, which thus controls the water level of the reservoir. An oil shale-based (with rather high $\mathrm{CO} 2$ emissions) energy plant located in the region also uses the reservoir's water for its cooling circuits.

The reservoir renews itself thirty-five times a year, because in addition to the Narva River, the Pljussa, Pjata, Must, and Boroni Rivers also constantly bring in fresh water. The overflow is directed on down the Narva River, shaping the contours of the town as it flows under three bridges that are simultaneously gateways and boundaries.

People living in Narva relate to the reservoir in a variety of ways. Some dacha allotments have been established next to it, and this allows for a particular engagement with nature, such as by growing one's own food or keeping chickens. Besides traditional gardening plots, there are also a series of boathouses adjacent to the reservoir, locally known as "Narva Venice", which appear as narrow, canal-stripe structures surrounded by metal storage buildings.

In July 2013, one of the authors, Tarmo, met the local neigbour Gennadi on the shore and took a boat trip on the reservoir. Before starting, Gennadi made a phone call to the border guard station informing them of his boat number and his intention to use it on the reservoir. As we slowly navigated from the canal to the reservoir, we had the chance to observe activities in the boathouses along the canal. For example, we passed one boat shelter that included a TV aerial and furniture, where an elderly man was spending some time on his own. These vernacular modifications and additional uses of the boathouses are often related to family recreational activities during the summer. During winter, however, Narva Venice and the surrounding dachas are empty because the fragile infrastructure that provides fresh drinking water does not support permanent living there.

On the open water, Gennadi pointed out several landmarks on each side of the border - such as the historical brick buildings of the Kreenholm textile factory in Estonia, the golden domes of an Orthodox church in Russia, different radar stations used by the border guards, and wind energy generators. Over the motor's noise, he described how the border regime splintered previously open waterways leading to a land full of seasonal berries and mushrooms. Nonetheless, and despite the heavily guarded border bisecting the reservoir and the Narva River, fishing remains a popular activity. Local fishermen anchor their boats in a row to avoid drifting onto the wrong side of the geopolitical boundary. The waterscape of Narva is also a space for cross-border smuggling of cigarettes, alcohol, and petrol, which are still cheaper on the Russian side.

At the end of our route, we faced the reservoir dam, and in the background the ruins of the Kreenholm textile complex and some transboundary electricity cables cutting across the horizon.

What can borders established in the aftermath of the disintegration of the Soviet Union tell us about the triangle of (geo)politics, nature, and infrastructure? As we 
demonstrate in our three snapshots, the process of frontier demarcation has not only made crossing the border more difficult, but has also affected socio-biological structures never meant to straddle borderlines. These structures - roads, pastures, a reservoir - have become severely hampered. We thus engage in a discussion on the role of geopolitical factors in the formation or disfigurement of infrastructural links, and the way in which certain socio-biological entanglements evolve as a consequence of fortuitous relations between the political and the organic and material. In all three cases, it is the new transboundary context that modifies the existing arrangements and temporal regimes.

\author{
Notes: \\ 1 "Gali" is the official name in Georgian and "Gal" in the Abkhazian language. \\ ${ }^{2}$ https://www.balcanicaucaso.org/eng/Areas/Abkhazia/Life-in-Gali-133720
}

\title{
References:
}

Jauhiainen, Jussi and Tarmo Pikner. 2009. "Narva-Ivangorod: Integrating and Disintegrating Transboundary Water Networks and Infrastructure." Journal of Baltic Studies 40 (3): 415-36. https://doi.org/10.1080/01629770903086293.

Martínez, Francisco. 2019 (forthcoming). "What's in a Hole? Voids out of Place and Politics below the State in Georgia." In Repair, Brokenness, Breakthrough: Ethnographic Responses, edited by Francisco Martínez and Patrick Laviolette. Oxford: Berghahn.

Cite as: Martínez, Francisco and Tarmo Pikner. 2019. "The Infrasctructural Side Effects of Geopolitics: Fortuitous Socio-Biological Modifications to Three European Borders." Roadsides 1: 18-27. DOI: https://doi.org/10.26034/roadsides-20190014. 


\section{Authors:}

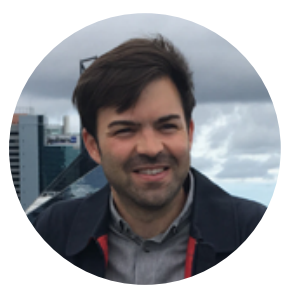

Francisco Martínez is a Postdoctoral Researcher at the University of Helsinki, editor of the Berghahn book series "Politics of Repair", and member of the editorial team of the Anthropological Journal of European Cultures. Francisco has edited several books and is the author of Remains of the Soviet Past in Estonia. An Anthropology of Repair, Forgetting and Urban Traces (UCL Press, 2018), which was awarded the Early Career Prize of the European Association of Social Anthropologists.

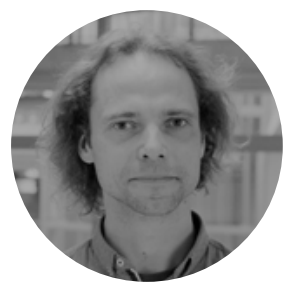

Tarmo Pikner holds doctoral degree in human geography, and pursues research on cross-border urbanity. Currently he works as Senior Researcher at Centre for Landscape and Culture at Tallinn University. His research topics include cultural-spatial transformations associated with global urbanisation, contested post-socialist environmental legacies, and the cultural dynamics of coastal areas. His current research activities are financed by the Estonian Research Council grant "Landscape approach to rurbanity" (grant no. PRG398). 
Roadsides is a collaborative online publishing platform designed to be a forum devoted to exploring the social life of infrastructure.

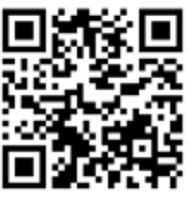

Visit us at: roadsides.roadworkasia.com E-Mail: roadsides@roadworkasia.com

\section{Editorial Team:}

Julie Chu (University of Chicago)

Tina Harris (University of Amsterdam)

Agnieszka Joniak-Lüthi (University of Zurich)

Madlen Kobi (Academy of Architecture, Mendrisio)

Nadine Plachta (Heidelberg University's South Asia Institute, Kathmandu Office)

Galen Murton (LMU Munich and James Madison University, Harrisonburg)

Matthäus Rest (Max-Planck-Institute for the Science of Human History, Jena)

Alessandro Rippa (CU Boulder)

Martin Saxer (LMU Munich)

Christina Schwenkel (University of California, Riverside)

Max D. Woodworth (The Ohio State University)

Collection no. 001 was edited by: Agnieszka Joniak-Lüthi

Copyediting: David Hawkins

Layout: Antoni Kwiatkowski and Chantal Hinni

\section{ISSN 2624-9081}

\section{Creative Commons License}

This work is licensed under a Creative Commons Attribution-NonCommercial-ShareAlike 4.0 International License.

\section{(C) $(1)(9$}

